\title{
Improvements in Symptoms and Quality of Life following Exercise Training in Older Adults with Moderate/Severe Persistent Asthma
}

\author{
Sian Turner ${ }^{a, b}$ Peter Eastwood ${ }^{a, c, e} \quad$ Angus Cook ${ }^{a, d}$ Sue Jenkins ${ }^{a, b, f}$ \\ a School of Physiotherapy and Curtin Health Innovation Research Institute, Curtin University of Technology, \\ ${ }^{b}$ Lung Institute of Western Australia and Centre for Asthma, Allergy and Respiratory Research, and Schools of \\ 'Anatomy and Human Biology, and d Population Health, University of Western Australia, and Departments of

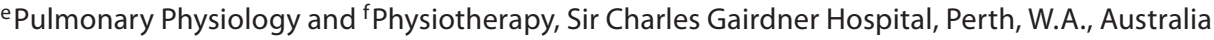

\section{Key Words}

Asthma • Exercise training • Rehabilitation • Quality of life •

Exercise tests

\begin{abstract}
Background: Some individuals with moderate/severe persistent asthma develop irreversible airway obstruction. These individuals present with dyspnoea, exercise intolerance and impaired quality of life (QOL), all of which could potentially be alleviated with exercise training. Objective: To investigate whether exercise training improves functional exercise capacity and QOL in middle-aged and older adults with fixed airway obstruction asthma (FAOA). Methods: 35 subjects aged $67.8 \pm 10.6$ years, with FEV $59 \pm 16 \%$ of predicted, were randomised to a 6 -week 'intervention' period of supervised exercise training $(n=20)$ or usual care $(n=15)$. This period was preceded by a 3-week run-in period during which asthma control was assessed weekly. Functional exercise capacity (6-min walk distance, 6MWD) and QOL (Asthma QOL Questionnaire, AQLQ) were measured before, immediately following and 3 months after the intervention period. Results: 34 subjects (exercise group, $\mathrm{n}=19$, and control group, $n=15$ ) completed the intervention period. Relative to the control group, the exercise group had greater improvements immediately following and 3 months after the intervention in the AQLQ symptom domain $(0.61, p=0.001$, and
\end{abstract}

0.57 points per item, $\mathrm{p}=0.005)$ and $A Q L Q$ activity limitation domain $(0.43, p=0.04$, and 0.55 points per item, $p=0.04$ ). $6 \mathrm{MWD}$ increased $(36 \pm 37 \mathrm{~m}, \mathrm{p}<0.01)$ in the exercise group immediately following training and remained elevated (34 $\pm 45 \mathrm{~m}, \mathrm{p}<0.01$ ) at the 3 -month follow-up. The magnitude of change in 6MWD between groups was not significant, despite no change in the control group. Conclusions: Supervised exercise training improves symptoms and $\mathrm{QOL}$ in adults with FAOA.

Copyright $\odot 2010$ S. Karger AG, Basel

\section{Introduction}

Asthma is one of the most common chronic conditions worldwide [1]. In adults, consequences of asthma include dyspnoea, wheezing and chest tightness on exertion and in response to other triggers, reduced exercise capacity and co-morbid conditions such as depression, anxiety and impaired quality of life (QOL) [2-4]. The disability associated with asthma has been reported to be greater in individuals with more severe disease, in those who are older and in those who have poorer control of their asthma [5]. A negative attitude to exercise is common due to a fear of symptoms occurring during or after exercise and to a lack of specific advice about exercise from health professionals. Such attitudes often lead to a 
detrimental health cycle which includes an aversion to taking part in physical activities, a low overall level of habitual activity and low physical fitness [6].

In clinical practice, middle-aged and older adults with moderate/severe persistent asthma are sometimes referred to pulmonary rehabilitation programs (PRP) with the goal of improving exercise capacity and QOL. An assumption underlying their participation in these programs is that the training protocol utilised and benefits achieved are similar to those observed in patients with chronic obstructive pulmonary disease (COPD), who represent the majority of individuals referred to PRP. To date, most studies evaluating exercise training in asthma have been undertaken in children or young adults with mild-to-moderate persistent disease. A meta-analysis of 13 randomised controlled trials of exercise training for asthma concluded that training improves cardiopulmonary fitness in the absence of any changes in lung function [6]. However, it was notable that the only two trials in adults were in young adults (mean age $<35$ years) with mild-to-moderate persistent asthma [6]. The intervention period lasted 3 or 4 months and neither of these studies included QOL as an outcome [6]. From the perspective of an individual with asthma, improvements in health-related QOL (HRQOL) represent the success of treatment in a more meaningful way than physiological end-points such as spirometric measures of lung function [7]. Consequently, optimising HRQOL has become an important component of asthma management [7]. It remains unknown whether exercise training improves exercise capacity or HRQOL in older adult populations with moderate/severe persistent asthma.

Defining the nature of disease in older adult populations with moderate/severe persistent asthma is made difficult because many exhibit permanent changes in lung function as a result of the chronicity of their asthma, and as such they could also be considered to have COPD $[8,9]$. In recognition of this we use the term fixed airway obstruction asthma (FAOA) to define a subject cohort with moderate/severe disease with a component of fixed airflow limitation. Such a definition is important because, despite similar symptomatology [10], individuals with COPD and FAOA are likely to demonstrate different responses to exercise. For example, well-preserved gas transfer is a characteristic of asthma [11] and therefore exercise-induced oxygen desaturation is unlikely to occur. In contrast, a proportion of individuals with COPD desaturate during exercise as a result of impairment in gas transfer and this contributes to exercise limitation $[12,13]$. Such differences suggest that exercise programs designed for COPD may not be appropriate for FAOA.

The present study was designed to test the hypothesis that supervised exercise training would result in improvements in functional exercise capacity and HRQOL in middle-aged and older adults with FAOA. In addition, we sought to examine the effects of exercise training on anxiety and depression, peripheral muscle strength and asthma control. Such outcome measures have not been collected in previous studies of exercise training in adults with asthma.

\section{Patients and Methods}

Subjects

Subjects were eligible to participate if they were at least 40 years old, had a diagnosis of moderate or severe persistent asthma with evidence of fixed airflow obstruction following a trial of maximum bronchodilator therapy and a trial of oral corticosteroids of at least 3-week duration. All subjects were required to be receiving long-term management by a respiratory physician with the diagnosis of asthma made by the physician based upon reported patterns of disease variability, trigger factors, atopy and responsiveness to medications. In addition, moderate/severe asthma with fixed airflow obstruction was defined by at least two of the following criteria: (i) forced expiratory volume in $1 \mathrm{~s}\left(\mathrm{FEV}_{1}\right)$ $<80 \%$ of predicted; (ii) $\mathrm{FEV}_{1} /$ forced vital capacity $<80 \%$ of predicted, or (iii) residual volume $>120 \%$ predicted. Subjects were required to be on a stable regimen of asthma medication, have a normal or raised gas transfer and report limitations in activities of daily living in response to the Asthma QOL Questionnaire (AQLQ) [14].

Exclusion criteria comprised: evidence of co-existing respiratory conditions; respiratory tract infection in the previous 4 weeks; current smokers or ex-smokers who ceased within the previous 2 years; smoking history $>15$ pack years; co-morbid conditions likely to reduce exercise capacity; current participation in $>30 \mathrm{~min} /$ day of moderate or vigorous exercise, and participation in a PRP in the previous 12 months. To minimise variations in asthma management, recruitment was restricted to patients from one respiratory physician at a metropolitan hospital and one private clinic where patients were managed by either of two respiratory physicians.

\section{Study Design}

Subjects meeting the above-defined criteria were enrolled in the trial, stratified by gender and randomised (http://www.randomizer.org) into an 'exercise group' and a 'control group'. All subjects then participated in a 3-week run-in period during which the Asthma Control Questionnaire (ACQ) [15] was completed each week. The investigators were blinded to the subjects' group allocation until subjects had completed the run-in period. The run-in period was extended if a subject reported an increase in asthma symptoms as reflected by their responses to the ACQ, a variation in $\mathrm{FEV}_{1}>10 \%$ or a change in their asthma medication. At the end of the run-in period, baseline measures of QOL, func- 
tional exercise capacity, anxiety and depression, and peripheral muscle strength were obtained at a single assessment during the subsequent 2 weeks. Following collection of baseline data, subjects participated in a 6-week exercise program (exercise group) or received standard medical care only (control group) over this time period. All baseline measures were repeated immediately following the 6-week intervention period (post-intervention assessment) and 3 months following completion of the intervention period (3-month follow-up). The timing of the assessments was delayed in the event that a subject was experiencing an exacerbation or other medical problem. This requirement ensured that all measurements were obtained when subjects were in a stable condition and taking their usual asthma medications.

Approval for the study was obtained from the Human Research Ethics Committees of Sir Charles Gairdner Hospital and Curtin University of Technology, and subjects gave written, informed consent prior to participation.

\section{Interventions}

\section{Exercise Group}

Subjects attended three exercise classes each week for 6 weeks in the Physiotherapy Department (Sir Charles Gairdner Hospital). The classes lasted for $80-90 \mathrm{~min}$ and were supervised by a physiotherapist. Any subjects requiring prophylactic bronchodilators prior to exercise were instructed to take their medication immediately prior to each class. Exercise was prescribed in accordance with the recommendations for individuals with COPD [16]. Specifically, classes commenced with a 10- to 15-min warm-up comprising slow walking within a temperature-controlled corridor and stretches. This was immediately followed by a 20 -min walking training prescribed at an initial intensity equivalent to $80 \%$ of the average walking speed achieved on the 6 -min walking test (6MWT) performed at the end of the run-in period (i.e. baseline assessment) [16]. Subjects were permitted to take short rests during the walking training if symptoms were intolerable. Following a 5 - to 10 -min cool-down period that comprised a 150-metre slow walk to the gymnasium, subjects participated in an exercise circuit comprising cycle ergometry training for $10 \mathrm{~min}$, stepups, wall squats and upper limb endurance training for a total of approximately $45 \mathrm{~min}$. The target training intensity for the circuit exercises was a rating of perceived exertion (RPE) of between 12 and 14 measured with the Borg 6-20 RPE scale [17]. When subjects reported a higher RPE, they continued to exercise at this intensity if their symptoms were tolerable. The intensity of the walking training and circuit exercises was increased each week within symptom tolerance [16]. The exercise program was extended to a maximum of 10 weeks for subjects who experienced an exacerbation of their asthma, or other problems, with the aim of subjects completing at least 14 supervised training sessions within a maximum of 10 weeks. All subjects randomised to the exercise group continued to receive standard medical care for their asthma.

At the end of the training period, each subject was provided with a written home exercise program based on the exercise intensities achieved during their final training week. Subjects were instructed to exercise on at least 3 days each week and were given a diary card to record their exercise sessions.

\section{Control Group}

Subjects randomised to this group continued to receive standard medical care for their asthma. These subjects were instruct- ed to continue with their usual activities and asthma management throughout the intervention period.

\section{Measurements}

Details of all current medications, number of emergency department presentations, hospitalisations and courses of oral corticosteroids for worsening asthma symptoms in the 12 months prior to recruitment were obtained for each participant. Resting lung function comprising spirometry (before and after bronchodilator therapy), static lung volumes and transfer factor were measured and repeated immediately following the intervention period.

\section{Outcome Measures}

The primary outcome measures for this study were HRQOL (self-complete version of the AQLQ) [14] and functional exercise capacity (6-min walk distance, 6MWD). The 6MWT was performed in accordance with current recommendations [18] using a 45-metre straight course. Subjects who had been instructed by their respiratory physician to take prophylactic bronchodilators prior to exercise took their bronchodilators prior to the 6MWT. Heart rate was monitored continuously (Polar a1, heart rate monitor, Polar Electro Oy, Kempele, Finland) during the 6MWT. Oxygen saturation $\left(\mathrm{S}_{\mathrm{p}} \mathrm{O}_{2}\right.$, Datex-Ohmeda 3775; GE Healthcare, Louisville, Colo., USA) and severity of dyspnoea on a $0-10$ scale [19] were recorded prior to and immediately following the test. Two tests were performed at each assessment, separated by $20-60 \mathrm{~min}$ of rest, and the greatest 6MWD was used in subsequent analyses.

Secondary outcome measures consisted of health status (Medical Outcomes Study Short-Form 36, SF-36, version 1), anxiety and depression (Hospital Anxiety and Depression Scale) [20], peripheral muscle strength and asthma control (ACQ). Peripheral muscle strength was assessed during a maximum isometric quadriceps contraction using a strain gauge (Falls Assessment Kit; Prince of Wales Medical Research Institute, Sydney, N.S.W., Australia) and hand grip was measured using a dynamometer (Jamar 5030 JI; Sammons Preston, Bolingbrook, Ill., USA). Measurements were made in triplicate on the dominant limb following standard protocols and the highest value was compared with reference data $[21,22]$.

\section{Sample Size and Statistical Analyses}

The specified sample size of 32 subjects was based on the capacity to detect a clinically significant change ( 0.5 points per item) in HRQOL (activity limitation domain of the AQLQ) and a 54 -metre change in $6 \mathrm{MWD}$ between groups with $80 \%$ power $(\alpha=0.05)$ [23-26]. Data were analysed according to the intentionto-treat principle. Three-month follow-up data were unavailable for 3 subjects in the control group and missing data for these subjects were replaced using the last observation carried forward method [27]. Baseline equivalence of groups was tested using unpaired t tests, Mann-Whitney tests and $\chi^{2}$ analysis as appropriate. Data for the primary and secondary outcome measures were analysed using a $2 \times 3$ repeated-measures ANOVA. Post hoc contrasts were specified for differences between groups at the postintervention assessment and at the 3-month follow-up. Data are expressed as means $\pm \mathrm{SD}$ with differences between groups expressed as means and 95\% confidence intervals. All statistical analyses were performed using SPSS software (version 16). 
Fig. 1. Study design and participant flow.

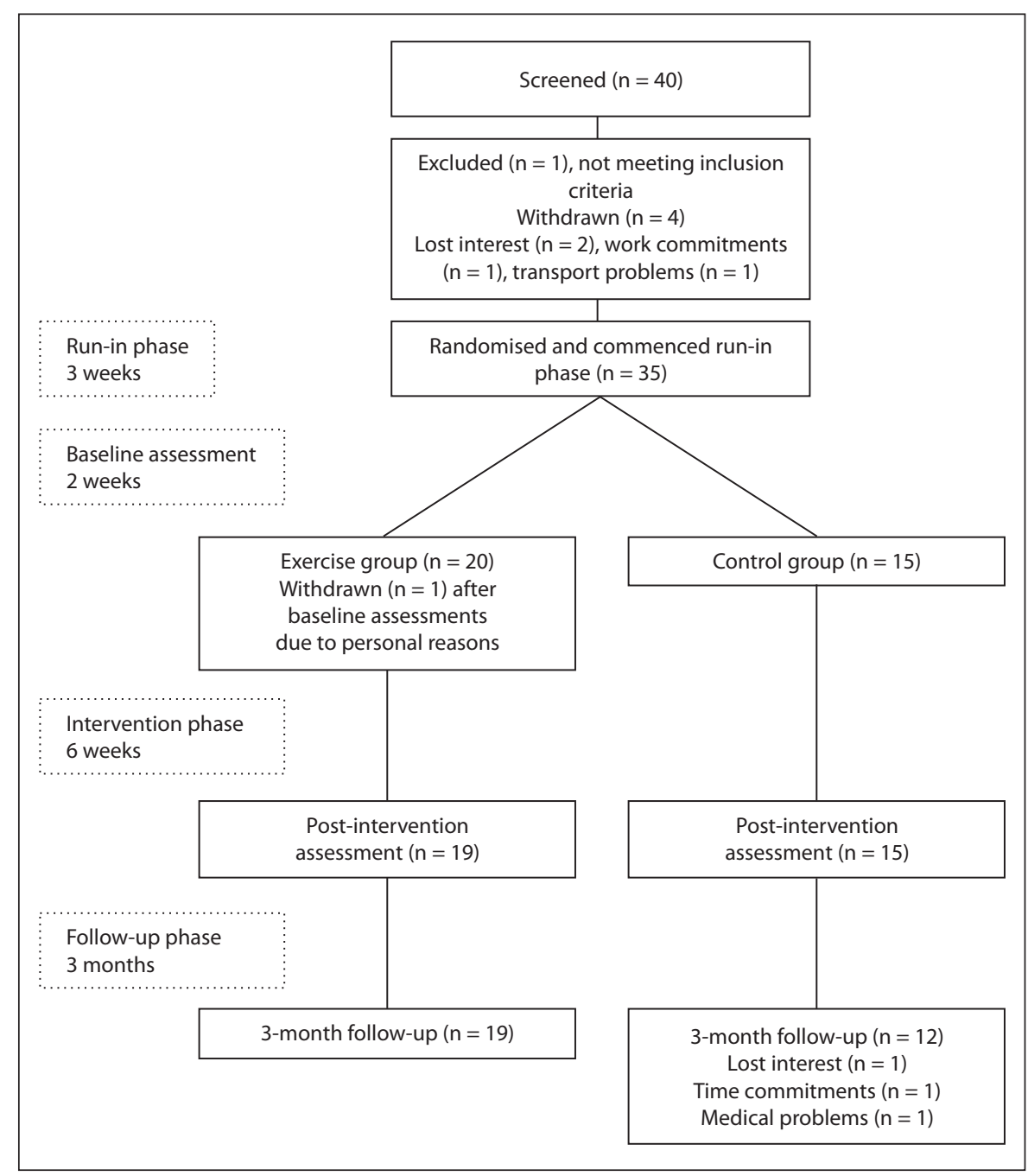

\section{Results}

During the period from August 2004 to July 2007, 266 individuals who satisfied the selection criteria were identified and were invited to participate in the study. Forty of these individuals provided informed consent and attended the initial screening. The main reasons for nonparticipation were lack of interest, time commitments and transport problems. Figure 1 summarises the flow of subjects through the study. For 5 subjects (exercise group $\mathrm{n}=4$ ), the run-in period was extended due to worsening asthma symptoms. There were no significant changes in ACQ scores in either group during the run-in period. Thirty-five subjects completed the run-in period and were randomised to the exercise $(n=20)$ or control $(n=$ 15) groups. One subject randomised to the exercise group withdrew from the study following the baseline assessments for personal reasons.

\section{Subject Characteristics and Baseline Measures}

Table 1 shows the characteristics of the 34 subjects (exercise group: $\mathrm{n}=19$ and control group: $\mathrm{n}=15$ ) who completed the intervention period. There were no significant differences between the groups in any of the variables examined. Five subjects, all ex-smokers, had undergone a recent high-resolution computed tomography scan that excluded emphysema. The remaining 6 ex-smokers had a median pack year history of 4 (range 0.5-13). Lung function data demonstrated moderate airflow limitation (mean $\mathrm{FEV}_{1} 60 \%$ of predicted) with evidence of lung hyperinflation and gas trapping (table 1). 
QOL, anxiety and depression scores and ACQ data are shown in table 2 . In both groups, the physical component summary score (SF-36, table 2) was lower than the normative mean value for adult Australians of 49.7 ( $\mathrm{p}<$ 0.001, one-sample t test) [28].

Subjects in both groups demonstrated a high level of functional exercise capacity with 6MWDs close to predicted values [29] and had well-preserved peripheral muscle strength (table 3). The percentage of subjects who reported exercising regularly, defined as walking at a leisurely pace for $30 \mathrm{~min}$ on at least 3 days each week, was 53 and $60 \%$ in the exercise and control groups, respectively.

\section{Effects of Training}

The intervention period was extended for 5 subjects in the exercise group because of asthma exacerbation ( $\mathrm{n}=$ 2 ), problems attending classes due to work commitments $(\mathrm{n}=2)$ and foot infection $(\mathrm{n}=1)$, and in 2 subjects in the control group because of an asthma exacerbation. No severe episodes of wheezing or chest tightness requiring medical intervention occurred in any of the subjects during the supervised training sessions.

AQLQ scores at baseline and after intervention are given in table 2 and figure 2. Relative to baseline measures, all domains of the AQLQ improved $(\mathrm{p}<0.01)$ in the exercise group with the magnitude of improvement exceeding the threshold ( $\geq 0.5$ points per item) for the minimum clinically important difference [23]. In the control group the only domain to increase over this period was 'activity limitation' ( $p<0.01)$, remaining increased at the 3 -month follow-up $(\mathrm{p}<0.01)$. Relative to the exercise group, the magnitude of improvement in the symptom and activity limitation domains in the exercise group was significantly greater at the post-intervention assessment (symptoms, 0.61 points per item, 95\% confidence interval $0.26-0.97, \mathrm{p}=0.001$; activity limitation, $0.43,0.01-0.84, \mathrm{p}=0.04$ ) and at the 3-month follow-up (symptoms, $0.57,0.18-0.95, \mathrm{p}=0.005$, and activity limitation, $0.55,0.01-1.10, \mathrm{p}=0.04$, table 2, fig. 2).

Compared to the control group, there was a significant increase in the physical component summary score (SF36 data) immediately following training $(6.7,0.2-13.0$, $\mathrm{p}=0.04$; table 2). At the 3 -month follow-up, the improvement in the physical component summary score was maintained compared to baseline, but the difference between the exercise and control group was no longer significant (table 2). Anxiety decreased in the exercise group following training and remained below baseline at the 3 -month follow-up (both $\mathrm{p}<0.05$ ), however the differ-
Table 1. Characteristics of the 34 subjects at baseline assessment Exercise Control

$(\mathrm{n}=19) \quad(\mathrm{n}=15)$

\begin{tabular}{llc}
\hline Sex, males:females & $8: 11$ & $7: 8$ \\
Age, years $^{\mathrm{a}}$ & $65.3 \pm 10.8$ & $71.0 \pm 9.7$ \\
Body mass index $^{\mathrm{a}}$ & $28.6 \pm 5.0$ & $26.8 \pm 7.6$ \\
Smoking history, never:former & $14: 5$ & $9: 6$ \\
\hline
\end{tabular}

Resting lung function ${ }^{a}$

$\mathrm{FEV}_{1}$, litres

$1.7 \pm 0.6 \quad 1.6 \pm 0.7$

$\mathrm{FEV}_{1}, \%$ of predicted

FVC, litres

FVC, $\%$ of predicted

$\mathrm{FEV}_{1} / \mathrm{FVC}$, \%

FRC, litres

FRC, \% of predicted

TLC, litres

$59 \pm 16 \quad 60 \pm 16$

TLC, $\%$ of predicted

$\mathrm{RV}$, litres

$\mathrm{RV}, \%$ of predicted

$\mathrm{RV} / \mathrm{TLC}$

RV/TLC, \% of predicted

TLCO/VA, $\mathrm{ml} / \mathrm{min} / \mathrm{mm} \mathrm{Hg}$

$3.1 \pm 1.0$

$3.1 \pm 1.2$

$83 \pm 16 \quad 87 \pm 15$

$54 \pm 8 \quad 53 \pm 13$

$3.8 \pm 0.8 \quad 3.9 \pm 1.2$

$162 \pm 58 \quad 157 \pm 55$

$6.3 \pm 1.3 \quad 6.2 \pm 1.9$

$113 \pm 12 \quad 115 \pm 15$

$3.1 \pm 0.6 \quad 3.0 \pm 1.0$

$144 \pm 22 \quad 140 \pm 32$

$50 \pm 9 \quad 50 \pm 9$

$128 \pm 19 \quad 121 \pm 19$

Asthma medications and healthcare utilization, $n$

$\begin{array}{lll}\text { Long-acting } \beta \text {-agonists } & 18 & 15\end{array}$

Anticholinergics $\quad 2 \quad 3$

$\begin{array}{lrr}\text { Inhaled corticosteroids } & 18 & 15\end{array}$

Maintenance oral corticosteroids $\quad 1 \quad 1$

Leukotriene receptor antagonists $\quad 4 \quad 1$

Cromoglycate $\quad 2 \quad 2$

Theophylline

2

In the last 12 months

Courses of oral corticosteroids, $\mathrm{n} \quad 8 \quad 7$

ED presentations, $\mathrm{n}$

Hospital admissions, $\mathrm{n}$

34

$\mathrm{FVC}=$ Forced vital capacity FRC $=$ functional residual capacity; $\mathrm{TLC}=$ total lung capacity; $\mathrm{RV}=$ residual volume; $\mathrm{TLCO} / \mathrm{VA}=$ diffusing capacity for carbon monoxide corrected for alveolar volume; $\mathrm{ED}=$ emergency department.

${ }^{\text {a }}$ Data are means $\pm \mathrm{SD}$.

ence between groups did not reach statistical significance (table 2).

6MWD improved in the exercise group immediately following training $(\mathrm{p}<0.01$; table 3$)$ and remained above baseline at the 3 -month follow-up $(\mathrm{p}<0.01)$. Despite being no change in $6 \mathrm{MWD}$ in the control group at either time point, the magnitude of change in 6MWD between the exercise and control groups did not reach statistical significance (table 3 ). 
Fig. 2. Changes in HRQOL-AQLQ in the exercise group (-- ) and control group $(-)$ at post-intervention and 3-month follow-up assessments (increased score equates to an improvement). ${ }^{a} \mathrm{p}<0.05$, ${ }^{\mathrm{b}} \mathrm{p}<0.01$ vs. baseline; ${ }^{\mathrm{c}} \mathrm{p}<0.05$ exercise group vs. control group. a Symptoms. b Activity limitation. c Emotional function. d Environmental stimuli.

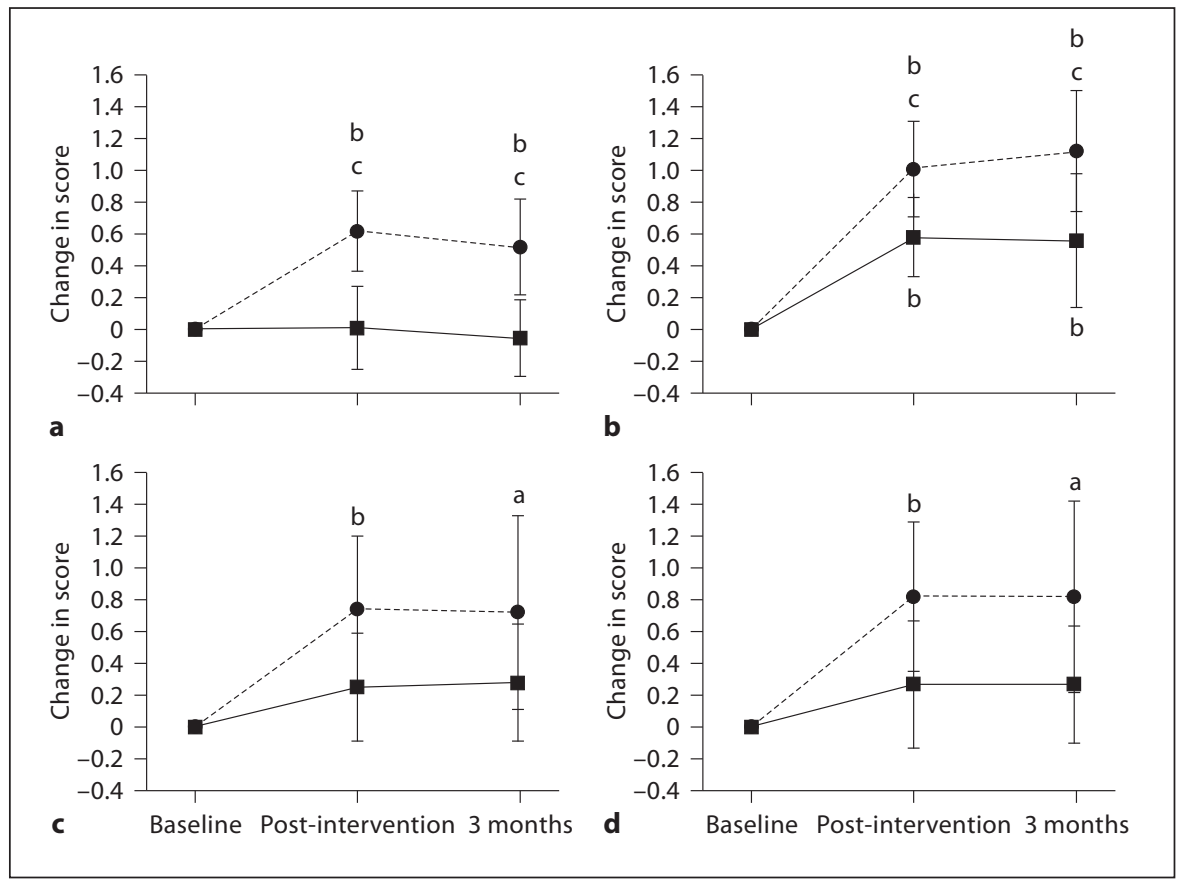

Resting lung function was not significantly different in either group at the post-intervention assessment compared to baseline values. There were no changes in body mass index in either group at the post-intervention or at the 3-month follow-up assessments. Asthma control was unchanged in either group when measured immediately following the intervention period or at the 3-month follow-up (table 2). There was no relationship between body mass index and asthma control in either group at the baseline assessment or at the post-intervention or followup assessments. Peripheral muscle strength was unchanged in both groups immediately following the intervention period and at the 3-month follow-up (table 3).

\section{Discussion}

This randomised controlled trial demonstrated significant improvements in disease-specific and generic measures of QOL in a group of middle-aged and older adults with FAOA following 6 weeks of supervised exercise. The improvements were seen immediately following training and still evident 3 months following training, and were significantly greater than any changes observed in a wellmatched control group. Exercise training resulted in a significant increase in 6MWD, however the magnitude of this change did not reach statistical significance compared with the control group.
Compared with previous studies that have investigated the effects of land-based exercise training in asthma, this study has a number of strengths: (i) the study cohort comprised middle-aged and older adults with FAOA - a cohort not previously examined; (ii) the rigorous study design with the inclusion of a 3-week run-in period ensured that subjects had stable asthma prior to randomisation and collection of baseline data, and (iii) the outcome measures included both disease-specific and generic QOL measures and mood state. Such outcome measures have not been collected in previous randomised controlled trials of exercise training in asthma, despite now being generally considered as important measures for asthma management [7].

\section{Exercise Training, QOL and Asthma Control}

Following training, the improvements in all domains of the AQLQ exceeded the threshold for a clinically important change. Relative to the control group, improvements in the symptom and activity limitation domains of the AQLQ were seen in the exercise group both immediately following training and at the 3-month follow-up. These findings indicate that exercise training was associated with a reduction in symptoms and an improved ability to undertake physical activities in daily life.

It was notable that the increase in the SF-36 physical component summary score observed immediately following training was not evident at the 3-month follow- 
Table 2. QOL, anxiety and depression and asthma control scores at baseline, immediately following the intervention period and at the 3-month follow-up assessment

\begin{tabular}{|c|c|c|c|c|c|c|}
\hline & \multicolumn{3}{|c|}{ Exercise $(n=19)$} & \multicolumn{3}{|c|}{ Control $(\mathrm{n}=15)$} \\
\hline & baseline & $\begin{array}{l}\text { post- } \\
\text { intervention }\end{array}$ & $\begin{array}{l}\text { 3-month } \\
\text { follow-up }\end{array}$ & baseline & $\begin{array}{l}\text { post- } \\
\text { intervention }\end{array}$ & $\begin{array}{l}\text { 3-month } \\
\text { follow-up }\end{array}$ \\
\hline \multicolumn{7}{|l|}{$A Q L Q$, points per item } \\
\hline Symptoms & $5.2 \pm 0.9$ & $5.9 \pm 0.7^{b, c}$ & $5.8 \pm 0.7^{\mathrm{b}, \mathrm{c}}$ & $5.6 \pm 1.3$ & $5.7 \pm 1.2$ & $5.6 \pm 1.4$ \\
\hline Activity limitation & $4.7 \pm 1.0$ & $5.7 \pm 0.8^{b, c}$ & $5.8 \pm 0.9^{\mathrm{b}, \mathrm{c}}$ & $4.7 \pm 1.1$ & $5.3 \pm 1.2^{\mathrm{b}}$ & $5.3 \pm 1.3^{\mathrm{b}}$ \\
\hline \multicolumn{7}{|l|}{ SF-36 (range 0-100) } \\
\hline Physical functioning & $56.1 \pm 21.6$ & $71.3 \pm 16.4^{\mathrm{b}}$ & $73.4 \pm 14.7^{\mathrm{b}}$ & $49.3 \pm 26.3$ & $55.3 \pm 25.9$ & $53.7 \pm 30.4$ \\
\hline Role physical & $46.1 \pm 32.6$ & $86.8 \pm 22.6^{\mathrm{b}}$ & $81.6 \pm 27.4^{\mathrm{b}}$ & $53.3 \pm 39.9$ & $50.0 \pm 45.3$ & $50.0 \pm 46.3$ \\
\hline Bodily pain & $79.4 \pm 21.9$ & $83.4 \pm 18.5$ & $80.6 \pm 20.8$ & $54.1 \pm 28.2$ & $66.2 \pm 23.0$ & $63.6 \pm 23.6$ \\
\hline General health & $61.0 \pm 21.5$ & $66.3 \pm 14.9$ & $66.8 \pm 22.2$ & $54.7 \pm 21.8$ & $57.5 \pm 20.8$ & $54.9 \pm 21.4$ \\
\hline Physical component score & $39.2 \pm 9.8$ & $47.1 \pm 6.9^{\mathrm{a}, \mathrm{c}}$ & $46.2 \pm 6.2^{\mathrm{a}}$ & $36.7 \pm 10.4$ & $38.4 \pm 11.0$ & $37.0 \pm 12.4$ \\
\hline Mental component score & $54.9 \pm 10.4$ & $55.0 \pm 7.0$ & $55.0 \pm 8.9$ & $49.6 \pm 12.5$ & $51.1 \pm 10.8$ & $52.4 \pm 10.6$ \\
\hline \multicolumn{7}{|l|}{ HAD (range 0-21) } \\
\hline Anxiety & $5.2 \pm 3.5$ & $3.4 \pm 3.2^{\mathrm{a}}$ & $3.9 \pm 3.2^{\mathrm{a}}$ & $5.9 \pm 3.1$ & $6.0 \pm 3.5$ & $4.9 \pm 3.8$ \\
\hline Depression & $3.3 \pm 2.8$ & $1.8 \pm 1.8$ & $2.2 \pm 2.8$ & $4.6 \pm 3.3$ & $4.1 \pm 2.9$ & $3.5 \pm 3.1$ \\
\hline ACQ (range 0-6) & $1.7 \pm 0.7$ & $1.5 \pm 0.6$ & $1.6 \pm 0.8$ & $1.7 \pm 1.0$ & $1.7 \pm 1.0$ & $1.8 \pm 1.2$ \\
\hline
\end{tabular}

Data are means $\pm \mathrm{SD} . \mathrm{HAD}=$ Hospital Anxiety and Depression Scale. ${ }^{\mathrm{a}} \mathrm{p}<0.05,{ }^{\mathrm{b}} \mathrm{p}<0.01$ vs. baseline; ${ }^{\mathrm{c}} \mathrm{p}<0.05$ exercise group vs. control group. A higher score on the ACQ indicates worse asthma control.

Table 3. Functional exercise capacity and peripheral muscle strength at baseline, immediately following the intervention period and at the 3-month follow-up assessment

\begin{tabular}{|c|c|c|c|c|c|c|}
\hline & \multicolumn{3}{|c|}{ Exercise $(n=19)$} & \multicolumn{3}{|c|}{ Control $(n=15)$} \\
\hline & baseline & $\begin{array}{l}\text { post- } \\
\text { intervention }\end{array}$ & $\begin{array}{l}\text { 3-month } \\
\text { follow-up }\end{array}$ & baseline & $\begin{array}{l}\text { post- } \\
\text { intervention }\end{array}$ & $\begin{array}{l}\text { 3-month } \\
\text { follow-up }\end{array}$ \\
\hline 6MWD, m & $569 \pm 88$ & $605 \pm 98^{b}$ & $602 \pm 102^{\mathrm{b}}$ & $522 \pm 111$ & $528 \pm 114$ & $535 \pm 122$ \\
\hline $6 \mathrm{MWD}, \%$ of predicted & $91 \pm 10$ & $96 \pm 9$ & $96 \pm 10$ & $85 \pm 15$ & $86 \pm 14$ & $87 \pm 16$ \\
\hline Peak heart rate, b.p.m. & $129 \pm 16$ & $134 \pm 18$ & $135 \pm 20$ & $127 \pm 20$ & $127 \pm 20$ & $132 \pm 21$ \\
\hline Quadriceps strength, \% of predicted & $84 \pm 30$ & $88 \pm 24$ & $92 \pm 23$ & $78 \pm 30$ & $75 \pm 32$ & $79 \pm 33$ \\
\hline Hand grip strength, $\%$ of predicted & $109 \pm 23$ & $109 \pm 20$ & $108 \pm 25$ & $110 \pm 27$ & $115 \pm 29$ & $105 \pm 28$ \\
\hline
\end{tabular}

Data are means $\pm \mathrm{SD} . \mathrm{S}_{\mathrm{p}} \mathrm{O}_{2}=$ Percutaneous oxygen saturation; ${ }^{\mathrm{b}} \mathrm{p}<0.01$ vs. baseline. 
up. This finding highlights the relatively short duration of any improvements despite subjects being provided with a home exercise program at the end of the supervised training period. Although any improvements may have been better maintained had subjects been offered a formal maintenance program, at present the role and recommended format of maintenance programs in patients with chronic lung disease is unclear [30].

It is difficult to compare our study findings with those of other studies of exercise training in adults with asthma as our subjects were significantly older [31-33] and had more severe airflow limitation [31,32]. In addition, the two studies that have reported improvements in HRQOL did not use a questionnaire specifically developed for individuals with asthma and included interventions other than exercise training, such as patient education, breathing retraining, relaxation and recreational techniques, or nutritional advice and psychological counselling $[25,31]$. Of note was that one of these studies did not include a control group [25], and both studies included asthma and COPD subject cohorts $[25,31]$. Our findings are, however, generally consistent with those of other studies that have found no effect of exercise training on lung function or asthma control [6].

\section{Exercise Training and $6 M W D$}

Despite an increase in 6MWD following exercise training of $36 \pm 37 \mathrm{~m}$ in the exercise group $(\mathrm{p}<0.01)$ and $6 \pm 38 \mathrm{~m}(\mathrm{p}=0.54)$ in the control group, the difference in magnitude of increase between the groups did not reach statistical significance. This is most likely a consequence of large variability in 6MWD between individuals, and a relatively small sample size. All subjects had a high 6MWD at baseline, potentially resulting in a ceiling effect for the 6MWT in this group of individuals. It is possible that an alternative exercise test not constrained by gait speed may be more appropriate in this group. The minimal important difference in 6MWD following pulmonary rehabilitation in COPD subjects has been reported to be $54 \mathrm{~m}$ based on a between-subject comparison [26], and more recently an analysis of data from seven trials found that a change of $35 \mathrm{~m}$ represented an important effect [34]. To date, no study has determined the threshold value for an important change in 6MWD in middleaged and older subjects with asthma.

Despite a similar level of resting hyperinflation (as measured by residual volume/total lung capacity) to that seen in subjects with moderate/severe COPD that we have studied [35], our asthmatic subjects achieved considerably higher 6MWDs and reported less dyspnoea at the end of the 6MWT. It is possible that differences in transfer factor and the magnitude of dynamic hyperinflation occurring during the 6MWT in patients with asthma compared to COPD may account for their different performances in the $6 \mathrm{MWT}[13,36]$. Further, over $50 \%$ of the study cohort reported that they walked on a regular basis, possibly contributing to the high 6MWDs.

\section{Limitations}

It is possible that the low recruitment rate in this study may have resulted in a potential bias in the study population. A significant proportion of potential subjects were in full- or part-time employment, and during the screening phase many of these individuals were concerned about the time commitment required if they were randomised to the exercise group. However, the level of attrition at the 3-month assessment appears comparable to that in other studies of exercise training in adults with asthma [31]. Another potential limitation is that subjects randomised to the control group were not formally monitored for any changes in their exercise habits. At the 6-week assessment, some of these individuals stated that they had been exercising more regularly, which may have contributed to the improvement in the activity limitation of the AQLQ compared to baseline. Similarly, as objective monitoring of physical activity was not performed, we are unable to determine whether the sustained improvement in 6MWD observed at the 3-month follow-up assessment in the exercise group was due to these subjects being motivated to continue to exercise regularly following cessation of the supervised training.

\section{Implications}

The findings of the present study suggest that individuals with FAOA who are referred to a PRP are likely to be able to tolerate higher intensities of exercise than their counterparts with moderate/severe COPD. We suggest that the role of pulmonary rehabilitation specialists for patients with FAOA is to screen for complicating factors, provide reassurance that exercise is safe and effective and, if available, offer referral to community-based exercise programs such as may exist for middle-aged and older individuals with other chronic conditions.

\section{Acknowledgements}

The authors acknowledge the support of Prof. Philip Thompson for his contribution to the development of this study, ongoing medical advice and assistance with subject recruitment; the staff of the Clinical Trials Unit at the Lung Institute of Western Aus- 
tralia for their administrative support; Mr. Peter McKinnon (statistician); Drs. Peter Bremner and Quentin Summers for assisting with subject recruitment, and the support of the Physiotherapy Department at Sir Charles Gairdner Hospital. Finally, we thank the subjects for participating in this study.
Sian Turner was funded by a National Health and Medical Research Council (NHMRC, Australia) Public Health Postgraduate Scholarship. Support was also received from the Asthma Foundation of Western Australia and the Sir Charles Gairdner Hospital Research Fund. Peter Eastwood is supported by an Australian NHMRC Senior Research Fellowship (No. 513705).

\section{References}

1 Global Strategy for Asthma Management and Prevention, Global Initiative for Asthma (GINA): GINA Report, Global Strategy for Asthma Management and Prevention 2008. www.ginasthma.org.

${ }_{2}$ Jenkins CR, Thompson PJ, Gibson PG, WoodBaker R: Distinguishing asthma and chronic obstructive pulmonary disease: why, why not and how? Med J Aust 2005;183:S35-S37.

-3 Adams R, Wakefield M, Wilson D, Parsons J, Campbell D, Smith B, Ruffin R: Quality of life in asthma: a comparison of community and hospital asthma patients. J Asthma 2001; 38:205-214.

4 Clark CJ, Cochrane LM: Assessment of work performance in asthma for determination of cardiorespiratory fitness and training capacity. Thorax 1988;43:745-749.

5 Van Ganse E, Laforest L, Pietri G, Boissel JP, Gormand F, Ben-Joseph R, Ernst P: Persistent asthma: disease control, resource utilisation and direct costs. Eur Respir J 2002;20: 260-267.

6 Ram FS, Robinson S, Black PN, Picot J: Physical training for asthma. Cochrane Database Syst Rev 2005;4:CD001116.

$\checkmark 7$ Juniper EF, Wisniewski ME, Cox FM, Emmett AH, Nielsen KE, O’Byrne PM: Relationship between quality of life and measures of clinical status in asthma: a factor analysis. Eur Respir J 2004;23:287-291.

8 McFadden ER: Natural history of chronic asthma and its long-term effects on pulmonary function. J Allergy Clin Immunol 2000; 105:S535-S539.

9 Backman KS, Greenberger PA, Patterson R: Airways obstruction in patients with longterm asthma consistent with irreversible asthma. Chest 1997;112:1234-1240.

10 Shepherd JM, Duddleston DN, Hicks GS, Low AK, Russell LD, Brown CA: Asthma: a brief overview. Am J Med Sci 2002;324:174179.

11 Hughes JMB: Assessing gas exchange. Chron Respir Dis 2007;4:205-214.

-12 Hadeli KO, Siegel EM, Sherrill DL, Beck KC, Enright PL: Predictors of oxygen desaturation during submaximal exercise in 8,000 patients. Chest 2001;120:88-92.

-13 Mohsenifar Z, Lee SM, Diaz P, Criner G, Sciurba F, Ginsburg M, Wise RA: Single-breath diffusing capacity of the lung for carbon monoxide. A predictor of $\mathrm{PaO}_{2}$, maximum work rate, and walking distance in patients with emphysema. Chest 2003;123:13941400.
14 Juniper EF, Guyatt GH, Epstein RS, Ferrie PJ, Jaeschke R, Hiller TK: Evaluation of impairment of health-related quality of life in asthma: development of a questionnaire for use in clinical trials. Thorax 1992;47:76-83.

15 Juniper EF, O’Byrne PM, Guyatt GH, Ferrie PJ, King DR: Development and validation of a questionnaire to measure asthma control. Eur Respir J 1999;14:902-907.

16 Nici L, Donner C, Wouters E, Zuwallack R, Ambrosino N, Bourbeau J, Carone M, Celli B, Engelen M, et al: American Thoracic Society/European Respiratory Society statement on pulmonary rehabilitation. Am J Respir Crit Care Med 2006;173:1390-1413.

17 Borg G: Perceived exertion as an indicator of somatic stress. Scand J Rehabil Med 1970;2: 92-98.

18 ATS Committee on Proficiency Standards for Clinical Pulmonary Function Laboratories: ATS Statement: guidelines for the sixminute walk test. Am J Respir Crit Care Med 2002;166:111-117.

19 Borg GAV: Psychophysical bases of perceived exertion. Med Sci Sports Exerc 1982;14:377381.

20 Zigmond AS, Snaith RP: The hospital anxiety and depression scale. Acta Psychiatr Scand 1983;67:361-370.

-21 Andrews AW, Thomas MW, Bohannon RW: Normative values for isometric muscle force measurements obtained with hand-held dynamometers. Phys Ther 1996;76:248-259.

22 Bohannon RW: Reference values for extremity muscle strength obtained by hand-held dynamometry from adults aged 20 to 79 years. Arch Phys Med Rehabil 1997;78:2632.

-23 Juniper EF, Guyatt GH, Willan A, Griffith LE: Determining a minimal important change in a disease-specific quality of life questionnaire. J Clin Epidemiol 1994;41:8187.

24 Rutten-van Molken MPMH, Custers F, Van Doorslaer EJA, Jansen CCM, Heurman L, Maesen FPV, Smeets JJ, Bommer AM, Raaijmakers JAM: Comparison of performance of four instruments in evaluating the effects of salmeterol on asthma quality of life. Eur Respir J 1995;8:888-898.

25 Foglio K, Bianchi L, Bruletti G, Battista L, Pagani M, Ambrosino N: Long-term effectiveness of pulmonary rehabilitation in patients with chronic airway obstruction. Eur Respir J 1999;13:125-132.
26 Redelmeier DA, Bayoumi AM, Goldstein RS, Guyatt GH: Interpreting small differences in functional status: the six minute walking test in chronic lung disease patients. Am J Respir Crit Care Med 1997;155:1278-1282.

27 Lachin JM: Statistical considerations in the intent-to-treat principle. Control Clin Trials 2000;21:167-189.

28 Australian Bureau of Statistics: 1995 National Health Survey: SF-36 Population Norms. Canberra, Australian Bureau of Statistics, 1997, catalogue No. 4399.0.

29 Jenkins S, Cecins N, Camarri B, Williams C, Thompson P, Eastwood P: Regression equations to predict 6-minute walk distance in middle-aged and elderly adults. Physiother Theory Pract 2009;25:516-522.

-30 Ries AL, Bauldoff GS, Carlin BW, Casaburi R, Emery CF, Mahler DA, Make B, Rochester CL, ZuWallack R, Herrevias C: Pulmonary rehabilitation. Joint AACP/AACVPR evidence-based clinical practice guidelines. Chest 2007;131:4S-42S.

- 31 Cambach W, Chadwick-Straver RVM, Wagenaar RC, van Keimpema ARJ, Kemper HCG: The effects of a community-based pulmonary rehabilitation programme on exercise tolerance and quality of life: a randomized controlled trial. Eur Respir J 1997;10: 104-113.

32 Cochrane LM, Clark CJ: Benefits and problems of a physical training programme for asthmatic patients. Thorax 1990;45:345-351.

33 Girodo M, Ekstrand KA, Metivier GJ: Deep diaphragmatic breathing: rehabilitation exercises for the asthmatic patient. Arch Phys Med Rehabil 1992;73:717-720.

-34 Puhan MA, Mador MJ, Held U, Goldstein R, Guyatt GH, Schunemann HJ: Interpretation of treatment changes in 6-minute walk distance in patients with COPD. Eur Respir J 2008;32:637-643.

- 35 Hill K, Jenkins SC, Cecins N, Philippe DL, Hillman DR, Eastwood PE: Estimating maximum work rate during incremental cycle ergometry testing from 6-min walk distance in patients with chronic obstructive pulmonary disease. Arch Phys Med Rehabil 2008; 89:1782-1787.

-36 Marin JM, Carrizo SJ, Gascon M, Sanchez A, Gallego B, Celli BR: Inspiratory capacity, dynamic hyperinflation, breathlessness, and exercise performance during the 6-minute walk test in chronic obstructive pulmonary disease. Am J Respir Crit Care Med 2001;163: 1395-1399. 